\title{
Abóbora ou Jerimum? Um Estudo Semântico Lexical
}

\author{
Abóbora o Jerimum? Un Estudio Semantico Lexical \\ Pumpkin or Jerimum? A Lexical Semantic Study
}

\author{
Maria José Nelo ${ }^{1}$ \\ Nayara da Silva Queiroz ${ }^{2}$ \\ Gilvan Santos Gonçalves ${ }^{3}$
}

\begin{abstract}
Resumo
Este trabalho de natureza geossociolingüística tem por objetivo investigar, no nível semântico-lexical, o léxico que abrange a questão 32 do questionário fonético-fonológico (QFF) do Projeto Atlas Linguístico do Maranhão do Maranhão. (ALiMA). “Aquele que cede no chão, grande (imita), com uma espessa e amarelada cor vermelha no interior e é cozido para comer, fazer doces? Este estudo justifica-se em vista dessa cucurbitácea, já cultivada por os portugueses durante o século XVI e conhecidos como menina, da Quaresma, porqueira, chilaougila (cf. CASCUDO, s / d.), ocupam um lugar no topo do menu habitual do Brasil, sendo utilizados no preparo de diversos pratos, como doces ( polpas em xaropes, marmeladas e queijadinhas), papas, sopas e guisados, além do uso de suas sementes como um tipo de lanche. Tudo isso é resultado do colono português. Para realizar o estudo, foi necessário um estudo bibliográfico. Pesquisa nas seguintes áreas do conhecimento: lexicologia, geossociolinguística, linguagem e cultura. A pesquisa de corpus, formada pelas respostas de 20 sujeitos de quatro áreas do Maranhão - São Luís, Pinheiro, Araioses e Brejo - selecionados por idade, sexo, escolaridade e local de nascimento, foi obtida a partir do banco de dados do Projeto ALIMA. Em suma, a pesquisa abrange as seguintes etapas: pesquisa bibliográfica, seleção de corpus e análise de dados. Como referencial teórico, buscouse os trabalhos de Fiorin (2008), Ferreira (2007), Ilari (2008), Tarallo (1986), Câmara Júnior (1972), Oliveira (2001) e Cascudo (s / d.) . Os trabalhos enfocam questões relacionadas ao léxico, às relações linguísticas e culturais e às denominações de abóbora / abóbora. Os resultados mostram a utilização, dentro do estado do Maranhão, das duas variações mais comuns no país: abóbora (e sua variante fonética - abóbra) de origem portuguesa e jerimum (sua variante fonética - jirimum) de origem indígena. Portanto, confirma-se no Maranhão o que Cascudo (s / d.) Postulou: abóbora e jerimum arnossônimos na maior parte do Brasil, especialmente nas regiões Norte e Nordeste, o que significa que não há mais diferença em relação ao aspecto das cucurbitáceas. A
\end{abstract}

${ }^{1}$ Doutora em Língua Portuguesa; Universidade Estadual do Maranhão- UEMA; São Luís, Maranhão- Brasil; email: marianelo@uol.com.br.

${ }^{2}$ Mestranda em Ensino; Universidade Vale do Taquari- UNIVATES; Lajeado, Brasil; e-mail: nayaraqueiroz01@hotmail.com.

${ }^{3}$ Graduando em Letras- Língua Espanhola, Língua Portuguesa e Respectivas Literaturas; Universidade Estadual do Maranhão- UEMA; São Luís, Maranhão, Brasil; e-mail: gilvansantosg@ outlook.com.br. 
saber, a designação foi utilizada antes para as cucurbitáceas redondas e globulares maiores que os jerimuns, e jerimum para os diversos aspectos de formas longas, cilíndricas e redondas. Ainda segundo Cascudo (s / d.), A abóbora é a denominação característica do sul, enquanto o jerimum é o favorito no norte. Este trabalho visa contribuir para a descrição do português brasileiro em particular, a variedade falada no Maranhão.

Palavras-chave: Abóbora; Jerimum; Léxico.

\section{Resumen}

Este trabajo de naturaleza geo-sociolinguística objetiva investigar, en el nivel semántico-lexical, las lexías que presentan el concepto de la cuestión 32 del cuestionario Fonético-Fonológico (CFF) del Proyecto Atlas Linguístico del Maranhão (ALiMA) - “... aquello que crece en el suelo, grande (mímica), con una cáscara gruesa rojo-amarillenta por dentro y que se cocina para comer, para hacer dulce?”. Se justifica esta investigación llevando en cuenta que esa cucurbitácea, ya cultivada por lo portugueses en el siglo XVI y conocida como niñade la Cuaresma, porqueira, chila o gila (cf. CASCUDO, s/d), ocupa un lugar de destaque en el menú rutinariode Brasil siendo usada en el preparo de diversos platos, como dulce (zapallos en almíbar,marmeladas, queijadinhas), papas, sopas, cocidos, además del uso de su semilla como una especie de copetine. Todo eso, resultado de la herencia del colonizador portugués. Para la realización de este estudio, fueron necesarias investigaciones bibliográficas en los siguientes campos de conocimiento: lexicología, geo-sociolinguística, lengua y cultura. El corpus de la investigación, constituido por las respuestas de 20 personas, de cuatro localidades del Estado del Maranhão -São Luís, Pinheiro, Araioses e Brejo - seleccionados por criterios de grupos de edad, sexo, escolaridad y naturalidad, fue extraído del banco de datos del Proyecto ALiMA. En síntesis, la investigación comprende las siguientes etapas: investigación bibliográfica, selección del corpus y análisis de los datos. Como referencial teórico, se buscó apoyo en los trabajos de Fiorin (2008), Ferreira (2007), Ilari (2008), Tarallo (1986), Câmara Junior (1972), Oliveira (2001) y Cascudo (s/d.), que enfocan cuestiones relativas al léxico, a la relación lengua/cultura y a las denominaciones para zapallo. Los resultados apuntan el uso, en el ámbito del Maranhão, de las dos variantes más recurrentes en el País: abóbora(y su variante fonética abobra), de origen portuguesa y jerimum (y su variante fonética jirimum), de origen indígena. Se confirma en Maranhão, por lo tanto, lo que postula Cascudo (s/d): abóboray jerimumson sinónimos en grande parte de Brasil, en especial en el Norte e Nordeste, lo que significa decir que no hay más distinción en lo que concierne al aspecto de la cucurbitácea. O sea, antes se utilizaba la denominación abóbora para las cucurbitáceas de forma globular y esférica y más grandes que los jerimuns y jerimum para aquellas de aspecto diverso, alargadas y cilíndricas o redondeadas. Aun segundo Cascudo (s/d), abóbora es la denominación característica del Sur, en cuanto jerimum es preferida en el Norte. Con este trabajo, se pretende contribuir para la descripción del portugués brasileño y en particular de la variedad hablada en Maranhão.

Palabras- clave: Abóbora; Jerimum; Léxico.

\section{Abstract}

This work of a geo-sociolinguistic nature aims to investigate at the semantic and lexical level, the lexicon that covers question 32 of the phonetic and phonological questionnaire (questionário Fonético- Fonológico (QFF)) by Maranhão's Linguistic Atlas Project (Projeto Atlas Linguístico do Maranhão (ALiMA). "The one which yields up on the ground, big (mimics), with a thick red yellowish color in the inside and is cooked for eating, making 
sweets? This study is justified in view of this cucurbit, already cultivated by the Portuguese during XVI century and known as menina, da Quaresma, porqueira, chilaougila (cf. CASCUDO, s/d.), holds a place at the top of Brazil's habitual menu, being used in the preparation of various dishes, like sweets (squashes in syrup, marmalades and queijadinhas), porridges, soups and stew, besides the use of its seeds as a type of snack.This is all the result of the Portuguese settler. In order to conduct the study, it was necessary a bibliographic research in the following areas of knowledge: lexicology, geo-sociolinguistic, language and culture. The corpus research, formed by the answers of 20 subjects from four areas of Maranhão - São Luís, Pinheiro, Araioses and Brejo selected by age, gender, education and place of birth, was obtained from ALiMA Project data base. In short, the research encompasses the following stages: bibliographic research, corpus selection and data analysis. As a theoretical referential, the works of Fiorin (2008), Ferreira (2007), Ilari (2008), Tarallo (1986), Câmara Junior (1972), Oliveira (2001) e Cascudo (s/d.) were sought for support. The works focus on matters related to the lexis, to the language and culture relations and the denominations for pumpkin/squash. The results show the use, within the state of Maranhão of the two most common variations in the country: abóbora (and its phonetic variant - abóbra) of Portuguese origin and jerimum (its phonetic variant - jirimum) of indigenous origin. Therefore it is confirmed in Maranhão what Cascudo (s/d.) has postulated: abóbora and jerimum ares ynonyms in most parts of Brazil, especially in the North and Northeast, which means that, there is no more difference regarding the cucurbit aspect. To wit, the designation abóborawas used before for the round and globular cucurbits bigger than the jerimuns, and jerimum for the diverse aspect ones of long, cylindrical, round shapes. Yet according to Cascudo (s/d.), abóbora is the characteristic denomination from the South, whereas jerimum is the favorite in the North. This work aims to contribute to the Brazilian Portuguese description in particular, the variety spoken in Maranhão.

Keywords: Pumpkin; Jerimum; Lexicon.

\section{INTRODUÇÃO}

A língua é um dos instrumentos de interação sociocomunicativa que o homem dispõe para se relacionar e, assim, podemos concebê-la como um elemento aglutinador da sociedade e da comunidade linguística. Nesse sentido, é por meio da relação língua/sociedade que evidenciamos o caráter dinâmico da língua e através dessa relação confirmamos nossa identidade como indivíduos pertencentes a um grupo social. Cabe inferir ainda, que a língua de uma determinada comunidade surge e se constrói junto com o modo de vê o mundo, sua historia e cultura está constantemente em processo de mudança.

Na visão de Câmara Junior, (1972, p.267) é possível afirmar que,

"A língua pode ser considerada como uma parte da cultura inseparável, que resulta no meio para operar e substituir, implicando a necessidade de conhecer a história da língua, os costumes ou habitat de uma comunidade e observando as particularidades".

Como afirma Câmara Junior, a língua é parte inseparável da cultura, pois identifica e define uma comunidade. É por meio dessa interação que é possível conceber o léxico como uma ligação entre a comunidade linguística e a sua história cultural. Nesse sentido é que escreve Oliveira e Isquerdo (2001, p. 9) que, “[...] o léxico de uma língua conserva uma estreita relação com a história cultural da comunidade. [...] na medida em que o léxico recorta realidades de mundo, define, também, fatos de cultura." por isso é que o léxico é um reflexo 
social com o qual identificamos a realidade que nos cerca, concretizado dessa forma, a relação língua, léxico e cultura.

Tendo em vista as ideias ora supracitadas, este estudo tem como objetivo investigar as respostas dada a pergunta 53, do questionário fonético-fonológico do Atlas Linguístico do Maranhão (ALiMA),“... aquilo que dá no chão, grande (mímica), com uma casca grossa vermelho-amarelada por dentro e que se cozinha para comer, para fazer doce?". Desse modo, esta pesquisa se insere no âmbito do Projeto Atlas Linguístico do Maranhão - ALiMA, no que concerne ao léxico maranhense, da fala de habitantes de quatro municípios integrantes da rede de pontos do ALiMA - São Luís, Pinheiro, Brejo e Araioses, cujos dados já foram coletados. Buscou-se também analisar os fatores que influenciam na manutenção dessas variantes no português falado no Maranhão.

\section{A ABÓBORA}

A abóbora é uma espécie cultivada da família Cucurbitácea e pertence ao gênero Cucurbita. As espécies de Cucurbita abóbora e moranga ${ }^{4}$ estão entre as mais antigas cultivadas na América. Por muitos anos, a abóbora constituiu a base da alimentação da civilização Olmeca (Chile), Asteca, Inca e Maia (Bisognin, 2002).

No Brasil, encontramos uma variedade de nomes dados às Cucurbitas, que se diferenciam pelo formato, tamanho, cor da casca, cor da polpa, firmeza, teor de amido, teor de matéria seca, capacidade de armazenamento, produção e sabor: desse modo, é possível encontrar denominações como Goianinha, Maranhão, Menina, Mini-Paulista,Caserta,MeninaPrecose,Telsukabuto,Kyoto,Coroa e Crioula.(MAIA, 2011).

Ainda segundo Cascudo (s/d), em outros países como a Espanha, a Itália, a França e a Inglaterra, a abóbora constitui-se também ingrediente de várias receitas culinárias. É interessante ressaltar que o fruto da aboboreira, não faz parte, apenas, da alimentação das camadas populares, mas também da aristocracia, onde a abóbora possuía espaço de destaque nos banquetes reais (cf. CASCUDO, s/d.).

Caracterizando as abóboras europeias, ainda de acordo com Cascudo (s/d), a leguminosa possuía forma arredondada, esférica e de grande tamanho. Antes de falarmos das características das abóboras brasileiras, é importante ressaltar que os indígenas de língua

\footnotetext{
${ }^{4}$ As morangas (Cucurbita maxima), que se diferem das abóboras (Cucurbita moschata) por possuírem folhas simples, sem divisão, com manchas "prateadas", haste arredondada e cortiço quando o fruto está maduro. As morangas são globulares achatados com gomos destacados, casca geralmente salmão e polpa alaranjada (FILGUEIRA, 2003).
} 
Tupi, chamavam a esse fruto de jerimum ${ }^{5}$. Este, de aspecto alongado, cilíndrico, em formato cônico, curvo, com extremidades sugerindo a imagem de um pescoço e também arredondado.

Com isso, esses dois nomes abóbora de origem portuguesa e Jerimum de origem indígena tornaram-se correntes no falar brasileiro. O quadro a seguir, produzido a partir de Beline $(2008)^{6}$, dá uma visão das variantes abóbora e jerimum encontradas nas regiões brasileiras.

Com isso, esses dois nomes abóbora de origem portuguesa e Jerimum de origem indígena tornaram-se correntes no falar brasileiro. O quadro a seguir, produzido a partir de Beline $(2008)^{7}$, dá uma visão das variantes abóbora e jerimum encontradas nas regiões brasileiras.

Figura 1 -A variação diatópica entre abóbora e jerimum nas regiões brasileiras.

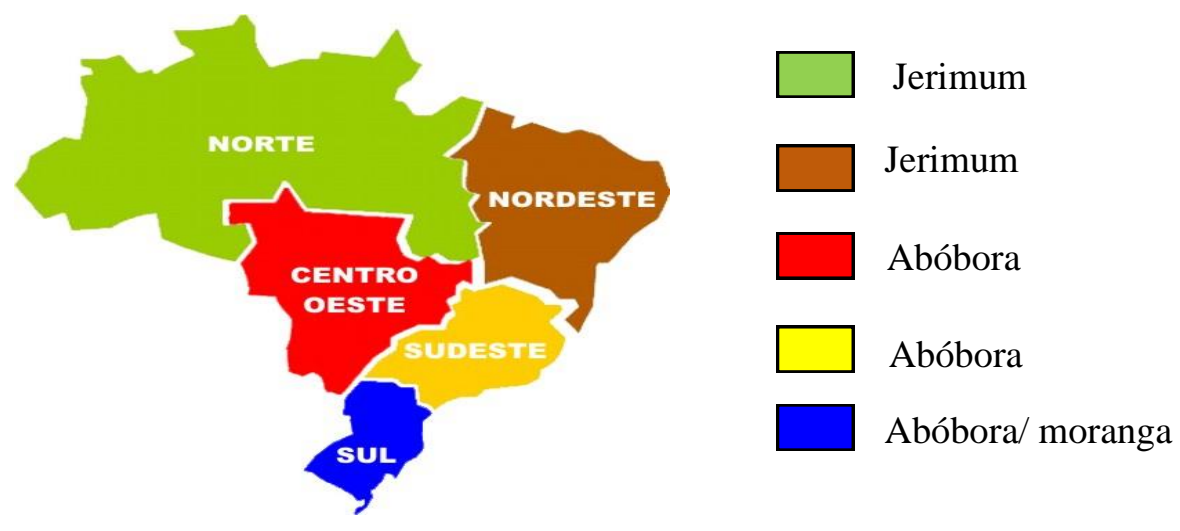

A abóbora ocupa um lugar de destaque no cardápio rotineiro do Brasil, sendo usada no preparo de diversos pratos como doces (abóboras em calda, marmeladas, queijadinhas), papas, sopas, cozidos, além do uso da semente como uma espécie de salgadinho.

Nas diferentes regiões do país, o consumo de abóbora tem aumentado, passando de 1,6 $\mathrm{kg}$ por pessoa para 4,2 kg. As abóboras e as morangas possuem grande valor socioeconômico em diferentes regiões do país, ocupando o $7^{\circ}$ lugar entre as hortaliças cultivadas no Brasil (IBGE, 2006) $)^{8}$.

\footnotetext{
${ }^{5}$ Designação indígena para jerimum- iuru( pescoço) e mum (apertado, estreito). (cf. CASCUDO, s/d.)

${ }^{6}$ Jerimum, palavra muito usada na Bahia, corresponde à abóbora, termo muito mais comum nos estados do Sul e Sudeste de nosso País (...)

${ }^{7}$ Jerimum, palavra muito usada na Bahia, corresponde à abóbora, termo muito mais comum nos estados do Sul e Sudeste de nosso País (...)

${ }^{8}$ Dados do censo agropecuário de 2006 realizado pelo Instituto Brasileiro de Geografia e Estatística (IBGE).
} 
Ainda de acordo com o IBGE, no Brasil, a área total cultivada com hortaliças está em torno de 700 mil hectares: as cucurbitáceas abóbora e moranga somaram, entre as hortaliças, com valor econômico, em 2006, uma produção com estimativa de 950 mil toneladas, numa área de aproximadamente 100 mil hectares. As abóboras e as morangas são cultivadas em todo território nacional, os principais produtores são os Estados de São Paulo (31,7\%), Bahia $(12,1 \%)$, Rio Grande do Sul (10,2\%), Maranhão (7,2\%), Minas Gerais (7,0\%) e Piauí $(6,5 \%)$ (IBGE, 2006).

No Maranhão, a cultura da abóbora vem se tornado muito significativa, devido ao aspecto climático ${ }^{9}$ que favorece a cultura durante todo o ano. Outro fator relevante para a produção da abóbora no estado é a sua forma de cultivo que não demanda muita habilidade técnica, devido ao manuseio, ao transporte,à pós-colheita e à resistência da hortaliça.

Entre os municípios maranhenses que mais se destacam no cultivo da abóboratemos Paraibano, Passagem Franca, Colinas e Pastos Bons. O município de Paraibano destaca-se como o de maior produção e de maior exportação do Estado.(CARNEIRO,2012)

A plantação de abóbora em Paraibano vem colaborando para o aumento da renda das pessoas do município, sendo maisuma forma de ganhar dinheiro dos pequenos, médios e grandes produtores. Os produtores exportam para vários estados do Nordeste e de outras regiões do País,por meio de compradores que cada anovem em busca do cultivo local, devido à forma de plantio da abóbora que ainda é artesanal. Um dos principais compradores de abóbora do Município é o estado de Pernambuco, que destina boa parte dessa produçãoaos Centros de Abastecimentos de Frutas e Verduras do Estado(CARNEIRO, 2012).

Diante da realidade sociocultural da abóbora no Brasil, e, em especial, no Maranhão, é necessária uma investigação no que concerne aos estudos da variação linguística, sobretudo no que diz respeito à variação denominativaparaabóbora. Nesse sentido, este estudo contribui para a descrição do português brasileiro e, em particular, da variedade do português falado no Maranhão.

\section{PROCEDIMENTOS METODOLÓGICOS}

O corpus desta pesquisa é constituído pelas respostas de 18 sujeitos de quatro localidades maranhenses - São Luís, Pinheiro, Brejo e Araioses - selecionados por critérios

\footnotetext{
${ }^{9}$ No caso das abóboras, o plantio pode ser realizado durante todo o ano nas regiões comclima quente. Nas regiões com clima ameno, o plantio é recomendado de outubro a janeiro(Serviço Brasileiro de Apoio àsMicro e Pequenas Empresas-SEBRAE.2002.
} 
de idade, sexo, escolaridade e naturalidade, e foi extraído do banco de dados do Projeto ALiMA.

A pesquisa compreende as seguintes etapas:

(i) Levantamento das designações dadas à questão n 32 do Questionário Fonéticofonológico do projeto ALiMA (“... aquilo que dá no chão, grande (mímica), com uma casca grossa vermelho-amarelada por dentro e que se cozinha para comer, para fazer doce?". );

(ii) Consulta ao Dicionário Houaiss da Língua Portuguesa (Houaiss et al. 2001);

(iii) Pesquisa em materiais técnicos (artigos científicos, relatórios técnicos) e informacionais (de divulgação) disponíveis em sites e publicações de órgãos governamentais(EMBRAPA, IBGE, CATÁLAGO e etc.) sobre a produção e o cultivo da abóbora no Brasil, mais especificamente, no Maranhão;

(iv) Análise em estudos culturais sobre a importância da abóbora para o Brasil, sobretudo nos feitos por Cascudo (s/d.);

(v) Consulta bibliográfica a trabalhos sobre a variação linguística, sobretudo no que concerne à variação no nível lexical, como os de Fiorin (2008), Ilari (2008), Tarallo (1986), Câmara Junior (1972) e Oliveira e Isquerdo (2001);

(vi) Análise das variantes encontradas no levantamento.

\section{DELIMITAÇÃO DO CORPUS}

\subsection{Localidades}

Para esta pesquisa, foram considerados os seguintes municípios que integram a rede de pontos do ALiMA e que recobrem as cinco mesorregiões do estado do Maranhão: São Luís, Pinheiro, Brejo e Araioses:

- Mesorregião Norte

São Luís (MA 1 ) - Microrregião Aglomeração Urbana de São Luís

- Mesorregião Norte

Pinheiro ( MA 3 ) - Microrregião Baixada Maranhense

- Mesorregião Leste

Brejo (MA 13) - Microrregião Chapadinha

- Mesorregião Leste

Araioses ( MA 14 ) - Microrregião Baixo Parnaíba Maranhense

\subsection{Os Informantes do ALiMA}


Os informantes do ALiMA são em número de quatro por localidades investigadas, exceto em São Luís, onde foram entrevistadas oito pessoas ${ }^{10}$. Os sujeitos participantes da pesquisa do ALiMA são selecionados de acordo com o seguinte perfil sócio-econômico:

(i) Pessoas de ambos os sexos, distribuídas em duas faixas etárias - faixa I, de 18 a 30 anos, e faixa II, de 50 a 65 anos;

(ii) Nível de escolaridade - sujeitos alfabetizados que cursaram, no máximo, até a 6- série do Ensino Fundamental; na capital, foram acrescidos mais quatro sujeitos com ensino superior completo;

(iii) Naturais das localidades pesquisadas, devendo não ter se afastado por mais de um terço da vida; os pais, preferencialmente, devem ser natos da comunidade. Para efeito desta pesquisa, selecionamos 18 informantes.

\subsection{Instrumentos de pesquisa}

\subsubsection{Questionário}

Os dados do ALiMA são obtidos mediante a aplicação de três questionários, organizados por nível de análise linguística - fonético-fonológico (QFF), semântico-lexical (QSL) e morfossintático (QMS), além de questões de pragmática, discurso semidirigido e questões metalinguísticas. Para este estudo, será considerado apenas o QFF. O questionário fonéticofonológico do ALiMA é composto por 159 questões que buscam investigar os fenômenos fonéticos e fonológicos do português. Geralmente, a questão 32 do QFF é investigada no sentido de observar a redução de vocábulos proparoxítonos, como abóbora, fígado entre outros.

\subsubsection{A ficha do informante}

A ficha possui perguntas relacionadas a aspectos socioeconômicos dos sujeitos da pesquisa, tais como: dados pessoais do informante - nome, alcunha, idade, sexo, naturalidade, escolaridade, endereço, estado civil, profissão, local onde desenvolve suas atividades laborais, contatos com meios de comunicação e lazer.

\subsubsection{A ficha da localidade}

A ficha contém informações sobre a localidade pesquisada, de modo que se possa ter um perfil do município que leve em conta dados de natureza histórica, social e econômica,

\footnotetext{
${ }^{10} \mathrm{Na}$ capital, são incluídos quatro sujeitos com curso superior completo: essa escolaridade foi levada em consideração, na capital, por ser onde há maior densidade populacional e o número de pessoas com nível superior é mais significativo para representação do grupo.
} 
tais como: nome oficial do município, gentílico, população, atividades econômicas predominantes, infraestrutura, características demográficas e históricas do município.

\subsubsection{Análise dos dados}

Fizemos a análise dos dados coletados e verificamos a relação das variantes comas localidades pesquisadas. Com base na análise, fizemos a distribuição diatópica das variantes.

\section{O LÉXICO E A VARIAÇÃO LINGUÍSTICA}

As relações que se formam entre língua/cultura faz com o que o léxico, numa perspectiva comunicativa, seja o meio pelo qual uma comunidade interaja entre si. Em resumo, ele constitui “(...) a representação linguística do mundo dos objetos biofísicos e socioculturais (...)" (BARBOSA, 1986, p. 81).

As variações linguísticas estão presentes em qualquer sistema linguístico, o que faz com que a língua seja dinâmica, e podemos perceber essas variações em mais de uma forma, essas variações pode ser percebida, no contato com pessoas, entre faixas etárias, níveis de escolaridades e sexo diferente. Porém, não é só pelo aspecto social que a variação é perceptível, mas também por meio de aspectos linguístico. Nesse sentido, o léxico é um dos principais meios pelos quais o homem expressa suas ideias e formas de ver o mundo. A variação linguística, no nível lexical, consiste na diversidade de denominações para umsentido, ou, conforme Tarallo (1986, p.8), “(...) são diversas maneiras de se dizer a mesma coisa em um mesmo contexto e com o mesmo valor de verdade (...)”. Portanto, é imprescindível um estudo acerca do léxico e da variação linguística no que diz respeito ao estudo semântico lexical.

\section{ANÁLISE DOS DADOS}

Considerando o objetivo desta pesquisa - investigar as respostas dadas à questão 53 do questionário fonético-fonológico do Projeto ALiMA -, elaborou-se um quadro descritivo que contém os resultados obtidos nas quatro localidades integrantes da rede de pontos do ALiMA, selecionadas para este estudo.

Cabe salientar que dentre os municípios pesquisados, São Luís dispõe de oito informantes, mas que, em nossa pesquisa, só constam seis (quatro do ensino fundamental e dois do ensino superior), considerando que os dados dos outros dois informantes ainda não foram coletados pelo Projeto.

Quadro 1 -Distribuição diatópica das lexias abóbora e Jerimum 


\begin{tabular}{|c|c|c|c|c|}
\hline \multirow{3}{*}{ 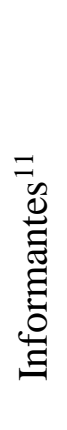 } & \multicolumn{4}{|c|}{ MESORREGIÕES MARANHENSES } \\
\hline & \multicolumn{2}{|c|}{ Norte } & \multicolumn{2}{|c|}{ Leste } \\
\hline & $\begin{array}{l}\text { Município } \\
\text { de } \\
\text { São Luís }\end{array}$ & $\begin{array}{l}\text { Municípi } \\
\text { o de } \\
\text { Pinheiro }\end{array}$ & $\begin{array}{c}\text { Município } \\
\text { de } \\
\text { Brejo }\end{array}$ & $\begin{array}{c}\text { Município } \\
\text { de } \\
\text { Araioses }\end{array}$ \\
\hline & abobra & abobra & $\begin{array}{c}\text { Aboba/abo } \\
\text { bra }\end{array}$ & abóbora \\
\hline & abóbora & abobra & abóbora & $\begin{array}{c}\text { Abobra/jer } \\
\text { imum }\end{array}$ \\
\hline & abóbora & abóbora & abóbora & abobara \\
\hline & $\begin{array}{l}\text { Jerimum/ } \\
\text { abóbora }\end{array}$ & abóbora & $\begin{array}{c}\text { Abóbora/ } \\
\text { jerimum/a } \\
\text { bobra }\end{array}$ & abóbora \\
\hline & abóbora & - & - & - \\
\hline & abóbora & - & - & - \\
\hline
\end{tabular}

Nesta amostra é notória a realização da variável abóbora entre os informantes utilizados para esta pesquisa e que a presença desta lexia é evidenciada também em ambos os sexos. Identificamos ainda que a variante jerimumsó apareceu entre as mulheres;esse

\footnotetext{
${ }^{11}$ Seguindo as orientações do projeto ALiB e do projeto ALiMA, os informantes recebem a seguinte numeração: os homens recebem números impares(1,3 e 5) e as mulheres, os números pares ( 2,4 e 6). Quanto as faixas etárias, os números 1, 2,5 e 6 correspondem aos informantes da faixa etária I ( 18-30) e os números 3 e 4, para os da faixa etária II ( 50-65).
} 
resultado seja talvez porque essa denominação é bem mais específica da culinária e que,podendo ser característico da culinária local.

No que diz respeito ao fator idade, ele se mostrou relevante, uma vez que entre os informantes da I faixa etária (ensino fundamental e superior), a denominação jerimum apareceu uma vez, em Araioses e entre os da II, aparece duas vezes, em São Luís e Brejo respectivamente.

Outro fator decisivo para a denominação da leguminosa é a escolaridade: os informantes que possuem o ensino fundamental apresentaram as duas denominações abóbora e jerimum e suas variantes fonéticas. Entres os informantes do ensino superior, predominou a denominação abóbora. Desse modo, os dados indicam que de acordo com o nível educacional, o indivíduo tende a usar determinado vocábulo, o que o leva a fazer a seleção da variante a ser utilizada.

Quando se analisa o fator localidade, é possível observar, em São Luís - a capital do Estado -, a denominação abóbora apareceu com maior recorrência, em confronto com a denominação jerimum, que aparece apenas uma vez na capital; com relação aos municípios do Continente Maranhense, a denominação abóbora também é mais recorrente; em contrapartida, com relação à denominação jerimum, no Continente, a denominação aparece com maior incidência, aparecendo duas vezes, em Araioses e Brejo.

\section{CONCLUSÃo}

Este estudo buscou no âmbito da relação língua/cultura e léxico contribuir para uma melhor compreensão do português falado no Maranhão. Para tanto, buscamos, no âmbito maranhense, confirmar o uso das duas variantes mais recorrentes no País: abóbora e jerimum. Com base na teoria do léxico e da variação, constatamos ainda a presença de variantes fonéticas - abobra, bobra, abobara e aboba. Verificamos ainda que, entre os 18 sujeitos da pesquisa, ocorreu um predomínioda variável abóbora, destoando com os dados encontrados em Beline (2008) para quem, no Nordeste, há um predomínio da variante jerimum.

\section{REFERÊNCIAS}

CÂMARA JUNIOR, Joaquim Mattoso. Língua e cultura. In: Dispersos. Rio de Janeiro: Fundação Getúlio Vargas, 1972, p. 265-273.

CASCUDO, Luís da Câmara. Abóbora e jerimum. Separata de: Revista de Etnografia, Porto, n. 12, p.1-6, s/d. 
FERREIRA, M.A.J.F. Abóboras, morangas e abobrinhas: estratégias para coleta, conservação $e$ uso. Brasília, abr.2007. Disponível em: http://www.embrapa.br/embrapa/imprensa/artigos/2007/artigo.2007-04-10.7554499366.

Acesso em: 12 abr. 2019.

BELINE, Ronald. A Variação Linguística. In: FIORIN, José Luiz. (org.) Introdução à Linguística: objetos teóricos. São Paulo: Contexto, 2008. v. 1.

ILARI, Rodolfo. Introdução ao estudo do léxico: brincando com as palavras. São Paulo: Contexto, 2008.

BIRDERMAN, Maria Tereza Camargo. As Ciências do Léxico. In: OLIVEIRA, Ana Maria Pires de Oliveira; ISQUERDO, Aparecida Negri. (orgs.) As ciências do léxico:lexicologia, lexicografia, terminologia. 2. ed. Campo Grande: UFMS, 2001.v. 1.p. 13-22.

TARALLO, Fernando. A pesquisa sociolinguística. São Paulo: Ática, 1986.

BARBOSA, Maria Aparecida. Lexicologia: aspectos estruturais e semântico-sintáticos. In: PAIS, Cidmar Teodoro et al. Manual de lingüística. São Paulo: Global, 1986, p. 81-125.

OLIVEIRA, Ana Maria Pires de Oliveira; ISQUERDO, Aparecida Negri. (orgs.) As ciências do léxico:lexicologia, lexicografia, terminologia. 2. ed. Campo Grande: UFMS, 2001.p. 0911 .

HOUAISS, Antônio; VILLAR, Mário de Salles; FRANCO, Francisco Manoel de Mello. Dicionário Houaiss da língua portuguesa. Rio de Janeiro: Objetiva, 2001.

CARNEIRO, Amaury. Safra da abóbora 2012 em Paraibano-MA, está no alge. 2012. . Disponível em: http://noticiasdeparaibanoma.blogspot.com.br/2012/04/safra-da-abobora-emparaibano-estar-no.html> Acesso em: 20 jun. 2019.

BISOGNIN, Da.Origin and evolution of cultivated cucurbits.v.32. Ciência Rural 2002. p. 715-723.

FILGUEIRA, Far. Novo manual de olericultura: agrotecnologia moderna na produção e comercialização de hortaliças. 2. ed. Viçosa: UFV. 2003.p. 412.

IBGE. Produção Agrícola. 2006. Disponível em: 〈http://www.ibge.gov.br>. Acesso em: 20 jun. 2019.

CATÁLOGO brasileiro de hortaliças: Saiba como plantar e aproveitar 50 espécies mais comercializadas no País. Brasília: Embrapa Hortaliças; Sebrae, 2010. 60 p. Disponível em:<http://www.ceasa.gov.br/dados/publicacao/Catalogo\%20hortalicas.pdf $>$. Acesso em: 20 jun.2019.

CATÁLOGO RURAL. Hortaliças - Abóbora. [S.1.], 2005. Disponível em:

<http://www.agrov.com/vegetais/hortalicas/abobora.htm>. Acesso em: 03 jun. 2019.

EMPRESA BRASILEIRA DE PESQUISA AGROPECUÁRIA. Cultivo da abóbora 
brasileirinha.Brasília: Embrapa Hortaliças, 2006. Disponível em: <http://www.cnph.embrapa.br/paginas/serie_documentos/outros/Cultivo_da_abobora_brasilei rinha.pdf $>$. Acesso em: 07 jun. 2019.

MAIA, Emanuel. Abóboras, morangas e pepinos.Rondônia: Universidade Federal de Rondônia - Curso de Agronomia, 2011. Disponível em:

<http://www.acagea.org/emanuelmaia2/ole2/cucurb/aboboras\%20morangas\%20e\%20pepin os.pdf>. Acesso em: 07 jun. 2019.

MIRANDA, Flávia Fernandes Ribeiro de. Efeito da frutificação induzida por 2,4-d em características Agronômicas dos frutos de abóbora 'tetsukabuto'. 2012. 62 f. Dissertação (Mestrado) - Universidade Federal do Tocantins, Gurupi. 2012. Disponível em: <http://www.uft.edu.br/producaovegetal/dissertacoes/FL\%C3\%81VIA\%20FERNANDES\%2 0RIBEIRO\%20DE\%20MIRANDA.pdf>Acesso em: 07 jun. 2019.

SERVIÇO BRASILEIRO DE APOIO ÀS MICRO E PEQUENAS EMPRESAS. Cultivo de hortaliças.[S.1.], [2002]. (Ponto de partida para inicio de negócio). Disponível em: $<$ http://www.biblioteca.sebrae.com.br/bds/BDS.

nsf/DCD36F0172EEE57E03256FB3004AD4 0B/\$File/NT000A494A.pdf>. Acesso em: 07 jun. 2019. 